\title{
Effects of the Velocity Sequences on the Friction and Wear Performance of PEEK-Based Materials
}

\author{
Leyu $\operatorname{Lin}^{1}$ (1) $\cdot$ Yuxiao Zhao ${ }^{1} \cdot$ Chi Hua ${ }^{1}$. Alois K. Schlarb ${ }^{1,2,3}$
}

Received: 5 January 2021 / Accepted: 28 April 2021 / Published online: 6 May 2021

(c) The Author(s) 2021

\begin{abstract}
In the present study, effects of the sliding velocity sequences on the friction and wear properties of pure polyetheretherketone (PEEK) and a PEEK hybrid composite were studied. It is demonstrated that the tribological properties of pure PEEK and its composite show a complex nature of the dependence on the velocity sequences in the studied range. The friction coefficient of PEEK is independent on previous velocity histories. In contrast, the testing sequence of the velocity exerts obvious impact on the friction coefficient of the PEEK composite at slow sliding velocities. With respect to the wear performance, the specific wear rate of pure PEEK exhibits a strong dependence on the sequences of the velocity only at the initial pv-levels. For the PEEK composite, its specific wear rate exhibits an obvious dependence on the previous velocity levels at a low nominal pressure of $1 \mathrm{MPa}$. When the pressure is increased to $8 \mathrm{MPa}$, the impact of the velocity sequences on the wear performance becomes insignificant. In addition, the tribological properties clearly correlate with the temperature of the tribosystem.
\end{abstract}

\section{Graphical Abstract}
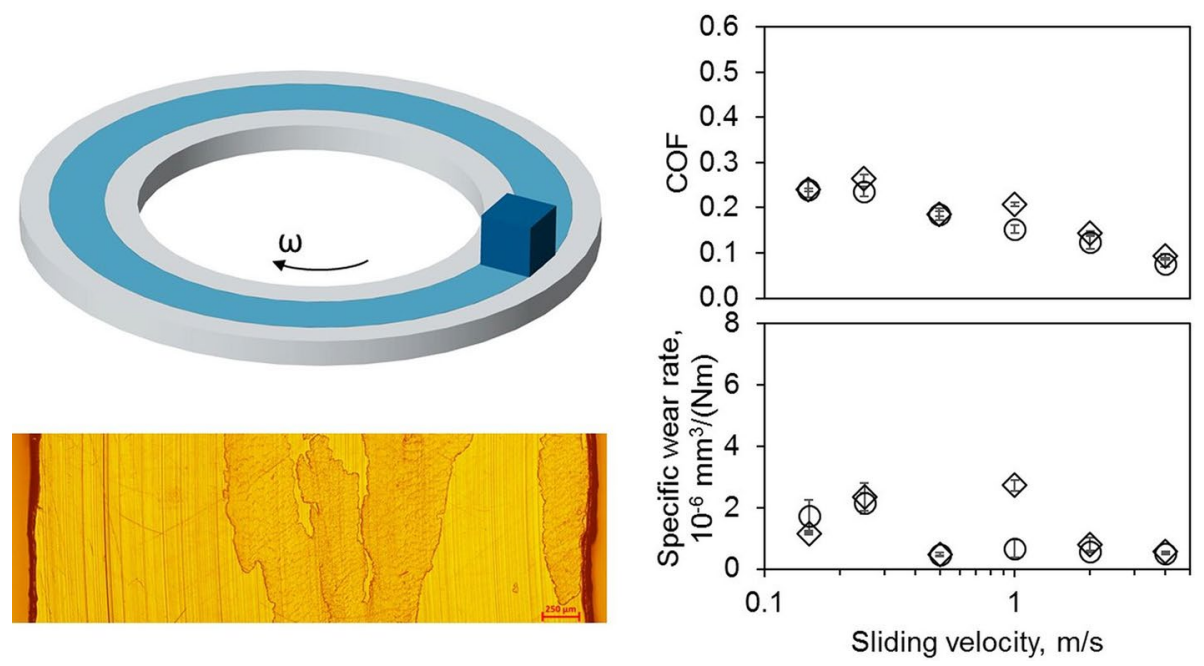

Keywords PEEK $\cdot$ Sliding velocity sequences $\cdot$ Friction and wear $\cdot$ Temperature

\section{Introduction}

Leyu Lin

leyu.lin@mv.uni-kl.de

Extended author information available on the last page of the article
PEEK is one of the high-performance thermoplastic polymers, which has been widely used as a friction-reducing and anti-wear material in mechanical engineering. It exhibits excellent mechanical performance and high thermal resistance [1-3]. However, PEEK needs to be modified by 
addition of suitable fillers, in order to meet the high requirements on the tribological applications in service. Carbon fibers (CFs) and solid lubricants, for instance graphite and polytetrafluorethylene (PTFE), reinforced PEEK composites are frequently utilized in the field, where self-lubrication and anti-wear properties are required [4-8]. In recent years, many studies have reported that incorporation of tiny inorganic particles into such PEEK composites leads to further improvement in their tribological properties [9-12]. Investigations on the tribological mechanisms reveal that stress reduction on the CFs [13], rolling of the particles [14] and isolation of the contact between CFs and counterpart asperities by the rigid particles [15] are the dominant factors improving the friction and wear performance of such PEEK tribocompounds. In addition, a well-formed transfer film leads to a reduction of the direct contact between the two sliding parts, and therefore alleviates the friction and wear in the polymer/steel tribosystems [16-19].

In the practical applications, such polymer-based triboparts are usually utilized under altering operating conditions owing to the rapid development of the modern technology and global energy-reduction, for example application of the start-stop technology in the commercial vehicles. Alternation of the load conditions, e.g., pressure (p), velocity (v), temperature, etc., does not occur regularly rather accidentally. Conventional tribological investigations were conducted at constant pv-factors in pre-defined testing period, which means that there are no load changes during the characterization. At the end of the test, the friction and wear properties of the tribomaterials were evaluated. Up till now, it is still not clear how do these load changes affect the subsequent tribological responses due to the distinct temperatures induced by the frictional heating and the initial formation of the transfer films on the counter body and so on. Studies of the load changes on the tribological behavior of polymer-based materials are quite sparse. In the study of Yeo [20], the friction and wear properties of polymer coatings were studied by stepwise load increasing experimental technique until the failure of the sample took place. The results demonstrated that it was possible to determine the pvfactors at failure by means of the load enhancing experiment. In addition, the tribofilms can clearly affect the friction and wear properties of the coatings. Similarly, Song et al. [21] have also studied the pv-limits of PTFE-based composites using load-increasing tests.

As it is well known that tribological properties are system properties, which are strongly dependent on the component geometries, several operating parameters and different fillers as well as the formation of the tribofilms. A reliable design and application of the polymeric tribomaterials can only be realized with in-depth characterizations under real application conditions. For various applications, the triboparts are often suffered under dynamically varied load conditions, as mentioned above. Therefore, the influence of the load changes or histories on the subsequent friction and wear performance within polymer/steel tribosystems needs to be clarified. In the present work, we studied the effects of distinct velocity sequences on the friction and wear behavior of PEEK-based materials. It is expected that our research results will pave a novel route of designing friction-reducing and anti-wear PEEK tribomaterials.

\section{Experimental Section}

VESTAKEEP 2000 G (Evonik Operations GmbH I Smart Materials, Germany) was used as PEEK matrix. In order to improve its anti-friction and anti-wear properties, graphite flakes and chopped carbon fibers (CFs) were incorporated into it. Moreover, submicro-sized zinc sulfide and titanium dioxide particles were also added into this PEEK composite, in order to create a synergetic effect for further improvement in the tribological performance. This PEEK composite has been proved as a high-performance tribocomposite in a previous study [22]. The compositions of the studied materials are listed in Table 1.

The PEEK composite was prepared on a co-rotated twin-screw extruder. Afterwards, both materials were

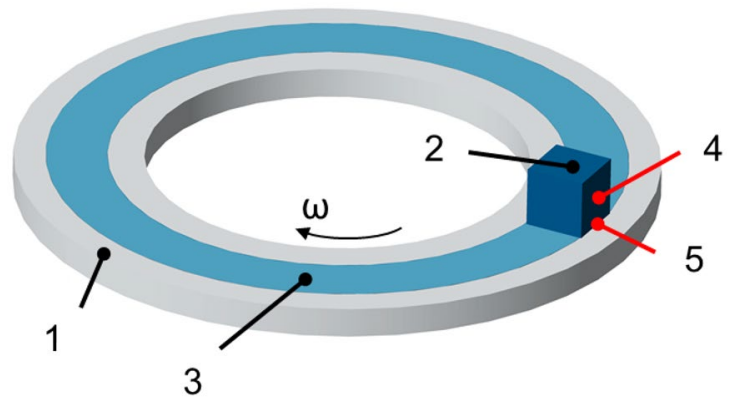

1. Steel washer

2. Polymer pin

3. Transfer film

4. Measuring point of the sample surface temperature

5. Position of the maximum contact edge temperature

Fig. 1 Schematic illustration of the PoD tribometer
Table 1 Compositions of the PEEK-based materials

\begin{tabular}{lcccccc}
\hline Designation & & PEEK & CF & Graphite & ZnS & $\mathrm{TiO}_{2}$ \\
\hline PEEK & wt.- $\%$ & 100 & - & - & - & - \\
PEEK composite & wt.- $\%$ & 60 & 10 & 10 & 10 & 10 \\
\hline
\end{tabular}


injection-molded to plates for preparing the tribological test specimens ( $4 \mathrm{~mm} \times 4 \mathrm{~mm} \times 4 \mathrm{~mm})$, as described in [23]. Their Friction and wear properties were characterized by means of a pin-on-disc (PoD) tribometer, which enables us to run the test with different sliding velocity sequences using one sliding pair, as it is schematically illustrated in Fig. 1. The polymer sample was slid against a 100Cr6 steel washer (LS2542, Schaefler Group, Germany). This steel washer exhibits a surface roughness $\left(R_{a}\right.$ value) of approximate $0.2 \mu \mathrm{m}$. During the test, the polymer sample surface temperature was recorded at the point of $1.5 \mathrm{~mm}$ above the contact area using a pyrometer (cf. Figure 1) [24]. This measured surface temperature served as the input temperature for calculating the maximum contact edge temperature using an analytical approach, which is detailed described in the supporting information.

In order to investigate the impact of the velocity sequences on the friction and wear performance of the PEEK-based materials, two sets of measurements were conducted: (a) stepwise increased velocity from 0.15 to 4 $\mathrm{m} / \mathrm{s}$ and (b) stepwise decreased velocity form 4 to $0.15 \mathrm{~m} / \mathrm{s}$. During the test, the nominal contact pressure was maintained at a constant value that was defined prior to the test. For pure PEEK, the maximal pv-combination were chosen as $2 \mathrm{MPa}$ and $2 \mathrm{~m} / \mathrm{s}$ due to its low thermal resistance based on the results of the preliminary tests. While the maximal pv-combination for the PEEK composite was selected as 8 $\mathrm{MPa}$ and $4 \mathrm{~m} / \mathrm{s}$ (pv-limit of the testing machine). The sliding time at the particular pv-level is defined as $10 / 6 / 6 / 4 / 4 / 4 \mathrm{~h}$ for six velocity levels, i.e., $0.15 / 0.25 / 0.5 / 1 / 2 / 4 \mathrm{~m} / \mathrm{s}$, which were selected based on our previous work [15].

During the sliding wear test, the height loss of the polymer sample was measured and recorded using a precise displacement transducer. The slope of the pin height loss versus sliding time curve in the steady stage is defined as the height loss rate $(\Delta h / t)$, which was utilized to calculate the specific wear rate $\left(w_{s}\right)$ by applying the following formula [25]:

$W_{s}=\Delta h /(t \cdot p \cdot v) \quad\left[\mathrm{mm}^{3} /(\mathrm{Nm})\right]$

Herein, it is well-worth pointing out that the temperature is constant within the tribosystem when a steady state was reached. In this case, the height loss took place in the "softened" polymer pin for which there were no more thermal expansion with increasing sliding time. Meanwhile, the formation and peeling off of the transfer films also got into a dynamically steady state. Therefore, the slope of the height loss curve in the steady state represented the net height loss rate due to wear. For calculating the mean values of the friction coefficient and specific wear rate, at least three measurements for each test condition were conducted.

After the tribological examinations, the sample worn surfaces and transfer films were inspected using a Nikon
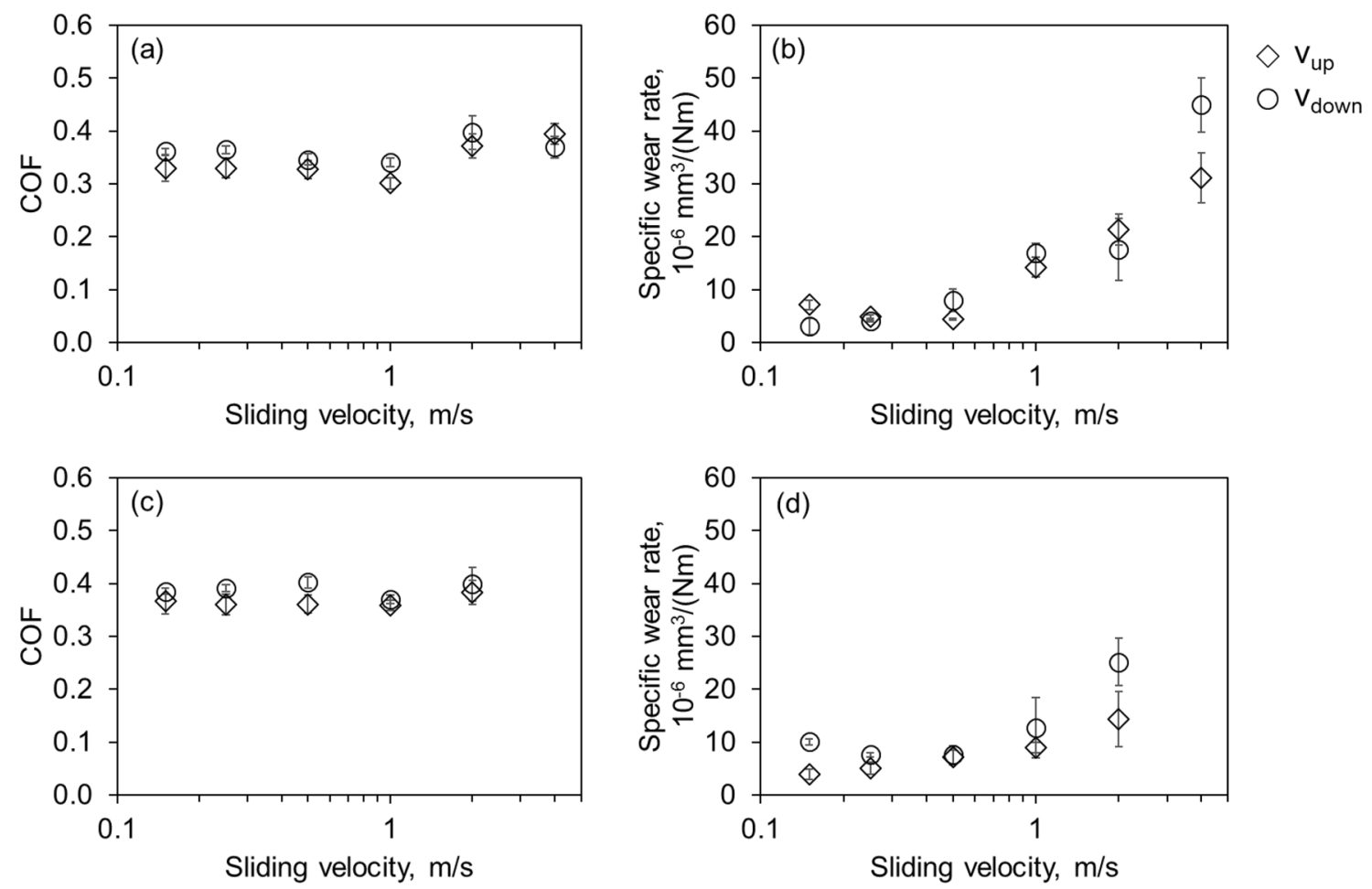

Fig. 2 Effects of the sequences of sliding velocity on the friction coefficient and specific wear rate of pure PEEK at $\mathbf{a} / \mathbf{b} 1 \mathrm{MPa}$ and $\mathbf{c} / \mathbf{d} 2 \mathrm{MPa}$ 
light microscope (ECLIPSE LV100POL, Japan) and Keyence laser scanning microscope VK-X1050 (Japan) for elucidating the tribological mechanisms.

Dynamic mechanical thermal analysis (DMTA) was performed on a Q800 apparatus (TA Instruments, USA) with single-cantilever mode with a heating rate of $2 \mathrm{~K} /$ min and frequency of $1 \mathrm{~Hz}$, in order to determine the glass transition temperature of the PEEK materials. The dimension of the sample was $17.6 \mathrm{~mm}$ long, $6 \mathrm{~mm}$ wide and 4 mm thick.

\section{Results and Discussion}

\subsection{Friction and Wear Properties of Pure PEEK}

Figure 2a shows the impact of the different sliding velocity sequences on the friction coefficient of PEEK at $1 \mathrm{MPa}$. As is shown, the friction coefficient of PEEK exhibits a relatively constant value of about 0.35 between $v=0.15$ and 1 $\mathrm{m} / \mathrm{s}$. Increasing the sliding velocity to $2 \mathrm{~m} / \mathrm{s}$ leads to a slight increase in the friction coefficient. Further increase in the velocity to $4 \mathrm{~m} / \mathrm{s}$ has no influence on the friction coefficient. Herein, it is of great interest to note that the friction coefficient of PEEK is almost independent on the sequences of the velocity in the studied range. Very similar trend can be observed at $2 \mathrm{MPa}$. PEEK presents quite similar friction coefficient of around 0.38 up to $2 \mathrm{~m} / \mathrm{s}$ independent on the absolute values and sequences of the sliding velocity (cf. Figure 2c).

Unlike the observations of the friction coefficient, the specific wear rate of pure PEEK shows an increasing trend with increasing velocity independent on the velocity sequences (cf. Figure $2 b$ and $d$ ). The maximum specific wear rate is always observed at the highest testing velocity in the studied range of the nominal pressures. With respect to the effect of the velocity sequences, the sequence of the sliding velocity exerts strong impact on the specific wear rate at $0.15 \mathrm{~m} / \mathrm{s}$ and $4 \mathrm{~m} / \mathrm{s}$. At $1 \mathrm{MPa}$ and $0.15 \mathrm{~m} / \mathrm{s}$, the specific wear rate presents a higher value when the sliding test was carried out with increasing velocity sequence, which is 2.3 times higher than that observed under the decreasing sliding velocity condition (cf. Figure 2b). However, the difference on the specific wear rate becomes less significant when the velocity was raised to $0.25,0.5$ and $2 \mathrm{~m} / \mathrm{s}$. At $4 \mathrm{~m} / \mathrm{s}$, the specific wear rate shows obvious dependence on the velocity sequences again. The wear rate measured with decreasing velocity sequence is significantly higher than that achieved with increasing one. When the same investigations were executed at $2 \mathrm{MPa}$, the specific wear rate exhibits inverse dependence on the velocity sequences at $0.15 \mathrm{~m} / \mathrm{s}$ compared to that at $1 \mathrm{MPa}$. In this case, the wear rate with reducing velocity sequence is higher than that with increasing one. Same dependence of the wear
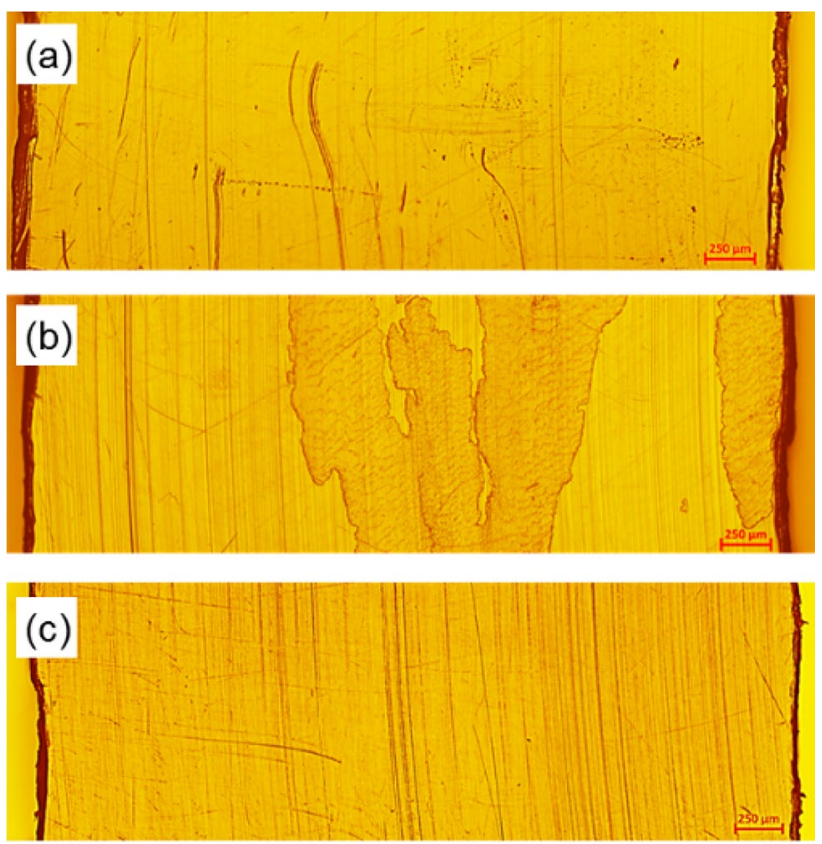

$500 \mu \mathrm{m}$

Fig. 3 Worn surface morphology of PEEK a with decreasing sliding velocity from $4 \mathrm{~m} / \mathrm{s}$ to $0.15 \mathrm{~m} / \mathrm{s}$ at $1 \mathrm{MPa}$, b with decreasing sliding velocity from $2 \mathrm{~m} / \mathrm{s}$ to $0.15 \mathrm{~m} / \mathrm{s}$ at $2 \mathrm{MPa}$ and $\mathbf{c}$ reference sample at a constant pressure of $2 \mathrm{MPa}$ and constant velocity of $0.15 \mathrm{~m} / \mathrm{s}$. The sliding direction is from the top to the bottom

rate on the velocity sequences is also observed at $2 \mathrm{~m} / \mathrm{s}$. In contrast, the wear rate of pure PEEK is non-susceptible to the velocity sequences at $0.25,0.5$ and $1 \mathrm{~m} / \mathrm{s}$, as can be seen in Fig. 2d.

Considering the specific wear rate of PEEK at a low sliding velocity of $0.15 \mathrm{~m} / \mathrm{s}$, it depends not only on the velocity sequences but also on the pressure level (cf. Figure $2 b$ and d). In order to elucidate this distinct dependence, the worn surfaces of the PEEK samples were characterized and are shown in Fig. 3. Plastic deformation of PEEK induced by strong frictional force can be clearly observed on the worn surface tested from $2 \mathrm{~m} / \mathrm{s}$ to $0.15 \mathrm{~m} / \mathrm{s}$ at $2 \mathrm{MPa}$ (cf. Figure $3 \mathrm{~b}$ ), which did not occurred at $1 \mathrm{MPa}$ from $4 \mathrm{~m} / \mathrm{s}$ to $0.15 \mathrm{~m} / \mathrm{s}$ (cf. Figure 3a). Temperature analysis based on the measured surface temperature of PEEK sample using the analytical model reported in [26] reveals that the maximum contact edge temperature reduces from 151 to $30{ }^{\circ} \mathrm{C}$ when the sliding velocity decreases from 2 to $0.15 \mathrm{~m} / \mathrm{s}$ at $2 \mathrm{MPa}$ (cf. Figure 4b). Herein, we should keep in mind that the high contact edge temperature correlates to the high contact temperature of the tribopair. Hence, this analytical result indicates that the temperature of the sliding pair at $2 \mathrm{~m} / \mathrm{s}$ within the contact region is above the glass transition temperature of pure PEEK $\left(150^{\circ} \mathrm{C}\right)$. After cooling to low temperature at $0.15 \mathrm{~m} / \mathrm{s}$, the PEEK shows much rougher worn 


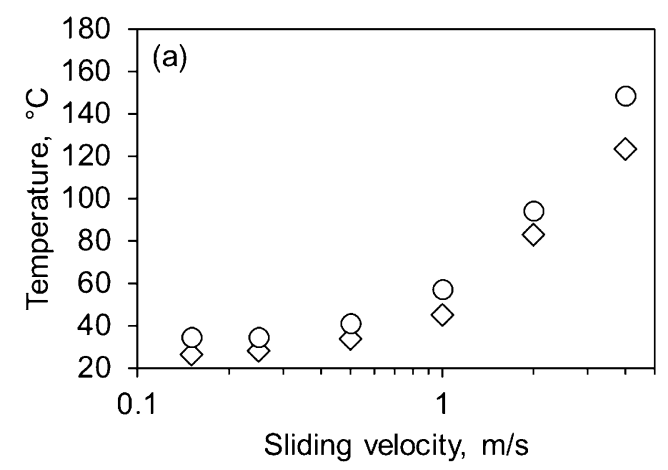

Fig. 4 Effect of the velocity sequences on the estimated maximum contact edge temperature of pure PEEK at a $1 \mathrm{MPa}$ and b $2 \mathrm{MPa}$. Parameters required for estimating the temperature can be found in

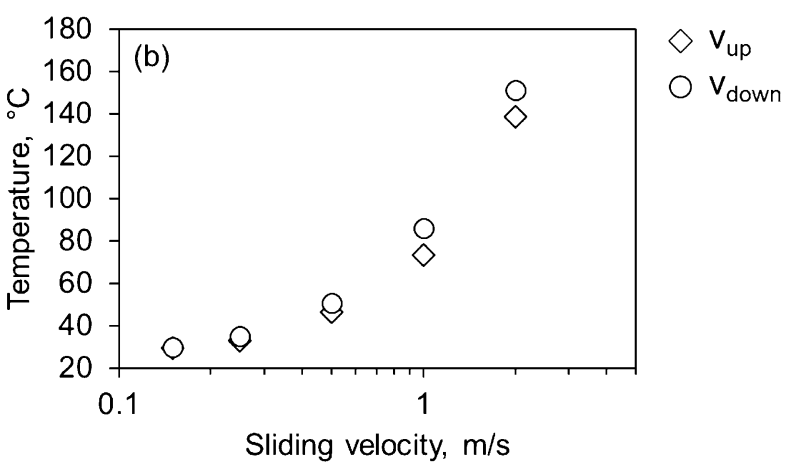

the supporting information. No standard deviations were provided in the diagrams. Because the temperatures were calculated from the mean values of the measured surface temperatures (cf. Figure 1)
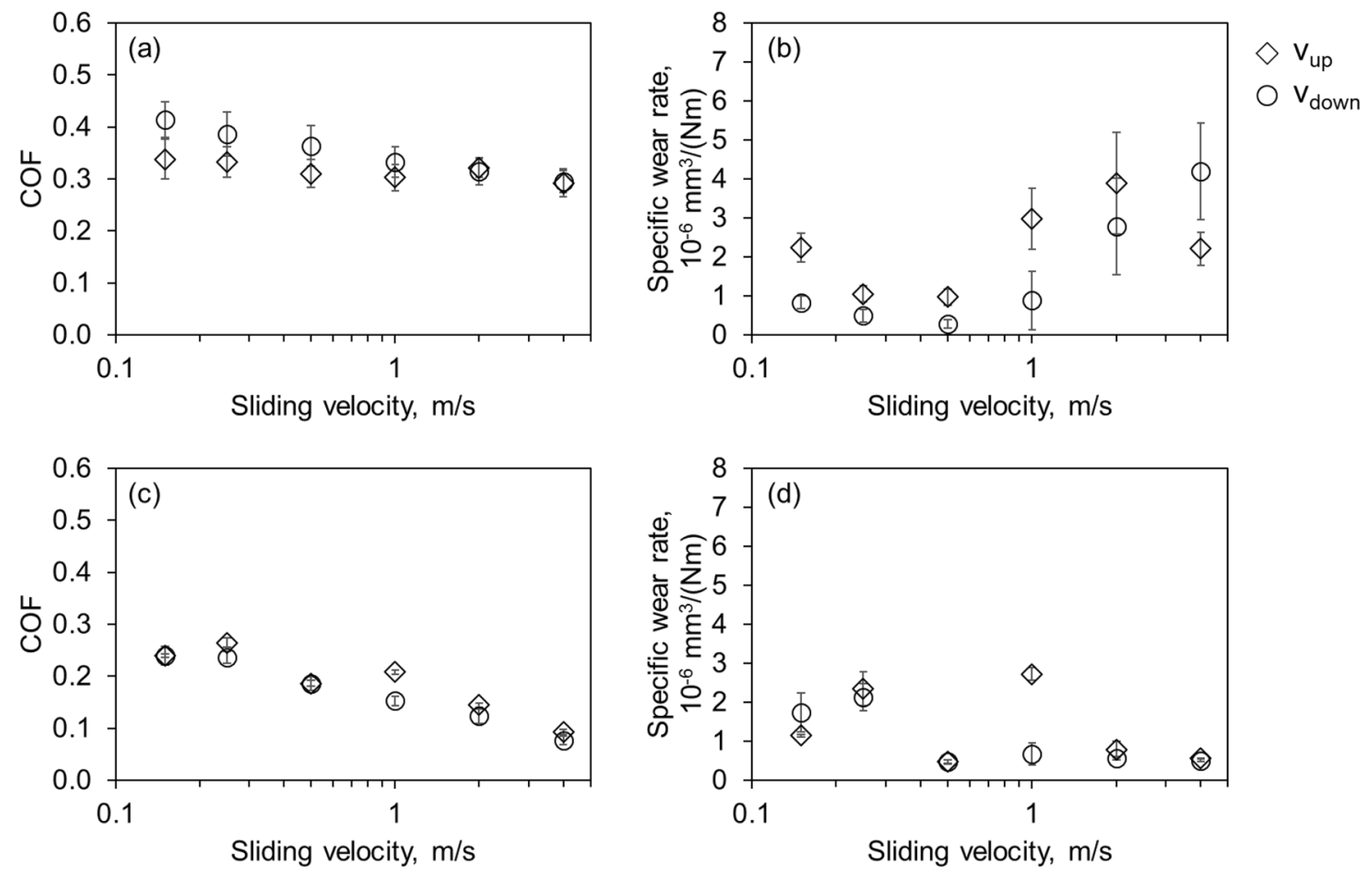

Fig. 5 Dependence of the friction coefficient and specific wear rate of the PEEK composite on the sliding velocity sequences at $\mathbf{a} / \mathbf{b} 1 \mathrm{MPa}$ and c/d $8 \mathrm{MPa}$

surface due to the plastic deformation indicating an abrasive wear compared to that with increasing velocity sequence at the same velocity (cf. Figure 3), which is closely related to the high wear with this velocity sequence. In contrast, the wear behavior of PEEK presents opposite dependence on the velocity sequences at $1 \mathrm{MPa}$ and $0.15 \mathrm{~m} / \mathrm{s}$, which can be attributed to the high amount of transferred materials required for filling the grooves on the virgin steel counterpart without any tribological histories and also the suboptimal quality of transfer films [27], in comparison to much less material transfer due to the previous sliding histories with decreasing velocity sequence. Herein, temperature is not the dominant factor for determining the wear performance of PEEK due to the low frictional force under this load condition, which is confirmed from the worn surface that no plastic deformation was induced during the sliding process (cf. Figure 3a). High specific wear rate at $1 \mathrm{MPa}$ and $4 \mathrm{~m} / \mathrm{s}$ with a fast starting velocity can be, on the one hand, ascribed to the high amount of transferred materials required for filling the grooves on steel surface, as aforementioned, on the other 
hand, it may be caused by the strong softening of polymeric material at high temperature (cf. Figure 4a), which reduces the shear resistance of the PEEK material. Therefore, the specific wear rate of PEEK shows obviously low wear resistance with decreasing velocity sequence at $4 \mathrm{~m} / \mathrm{s}$.

\subsection{Friction and Wear Performance of the PEEK Composite}

In comparison to the pure PEEK, the steady-state friction coefficient of the PEEK composite exhibits obvious dependence on the velocity sequences at $1 \mathrm{MPa}$ and slow sliding velocities. As can be seen in Fig. 5a, the friction coefficient measured with increasing velocity sequence is $19 \%$ lower than that measured by the decreasing one at a velocity of $0.15 \mathrm{~m} / \mathrm{s}$. With respect to the friction coefficients at $1 \mathrm{~m} / \mathrm{s}$ with distinct sequences, the distinction between them becomes less significant. The friction coefficient with enhancing velocity sequence is slightly lower than that with the reducing sequence. Moreover, the steady-state friction coefficients of the PEEK composite are non-susceptible to the velocity histories when the velocity is higher than $1 \mathrm{~m} / \mathrm{s}$ at $1 \mathrm{MPa}$, i.e., 2 and $4 \mathrm{~m} / \mathrm{s}$. They are nearly identical, which are independent on the velocity sequences. When the tribological investigations were conducted at $8 \mathrm{MPa}$, the friction coefficient presents almost no dependence on the velocity sequences except for $1 \mathrm{~m} / \mathrm{s}$ (cf. Figure $5 \mathrm{c}$ ). In addition, it is herein of great interest to observe that the steady-state friction coefficient decreases with increasing velocity independent on the previous velocity histories. The lowest friction coefficient is observed at $8 \mathrm{MPa}$ and $4 \mathrm{~m} / \mathrm{s}$, which is lower than 0.1 .

In terms of the dependence of the specific wear rate, the PEEK composite shows distinct dependence on the sliding velocity sequences compared to that of the friction coefficient at a pressure of $1 \mathrm{MPa}$. As is evident in Fig. 5b, the specific wear rate with increasing velocity sequence under each condition up to $2 \mathrm{~m} / \mathrm{s}$ is obviously higher than that with decreasing one. However, it presents an opposite trend at 4 $\mathrm{m} / \mathrm{s}$. At $8 \mathrm{MPa}$, the significant difference of the specific wear rate between distinct velocity sequences diminishes or even vanishes with an exception of $1 \mathrm{~m} / \mathrm{s}$ (cf. Figure 5d), whereat the specific wear rate with increasing speed sequence exhibits almost fourfold higher value compared to that with decreasing one. Moreover, the wear resistance at $0.15 \mathrm{~m} / \mathrm{s}$ exhibits contrary dependence on the velocity histories. The wear resistance measured with increasing velocity is $4 \%$ lower than that obtained with decreasing velocity sequence.

In order to clarify the distinct effects of the velocity sequences on the tribological responses of the PEEK composite at different pressures, both the worn surfaces of the composite sample and the corresponding transfer films were analyzed. As is shown in Fig. 6a, the worn surface of the PEEK composite examined with increasing velocity sequence at $1 \mathrm{MPa}$ and $1 \mathrm{~m} / \mathrm{s}$ exhibits much more serious ploughing furrows parallel to the sliding direction indicating
Fig. 6 Representative micrographs of $\mathbf{a} / \mathbf{b}$ polymer worn surfaces and $\mathbf{c} / \mathbf{d}$ transfer films formed on the steel counterpart at $1 \mathrm{MPa}$ and $1 \mathrm{~m} / \mathrm{s}$ with $\mathbf{a} / \mathbf{c}$ increasing and $\mathbf{b} / \mathbf{d}$ decreasing velocity sequence. The sliding direction is from the top to the bottom. The scale is equal in all the images. The number within the images indicates the developed interfacial area ratio $\left(\mathrm{S}_{\mathrm{dr}}\right.$ in percentage) of the transfer film and the values below them are the $S_{\mathrm{dr}}$ values (in percentage) of the steel disc as received
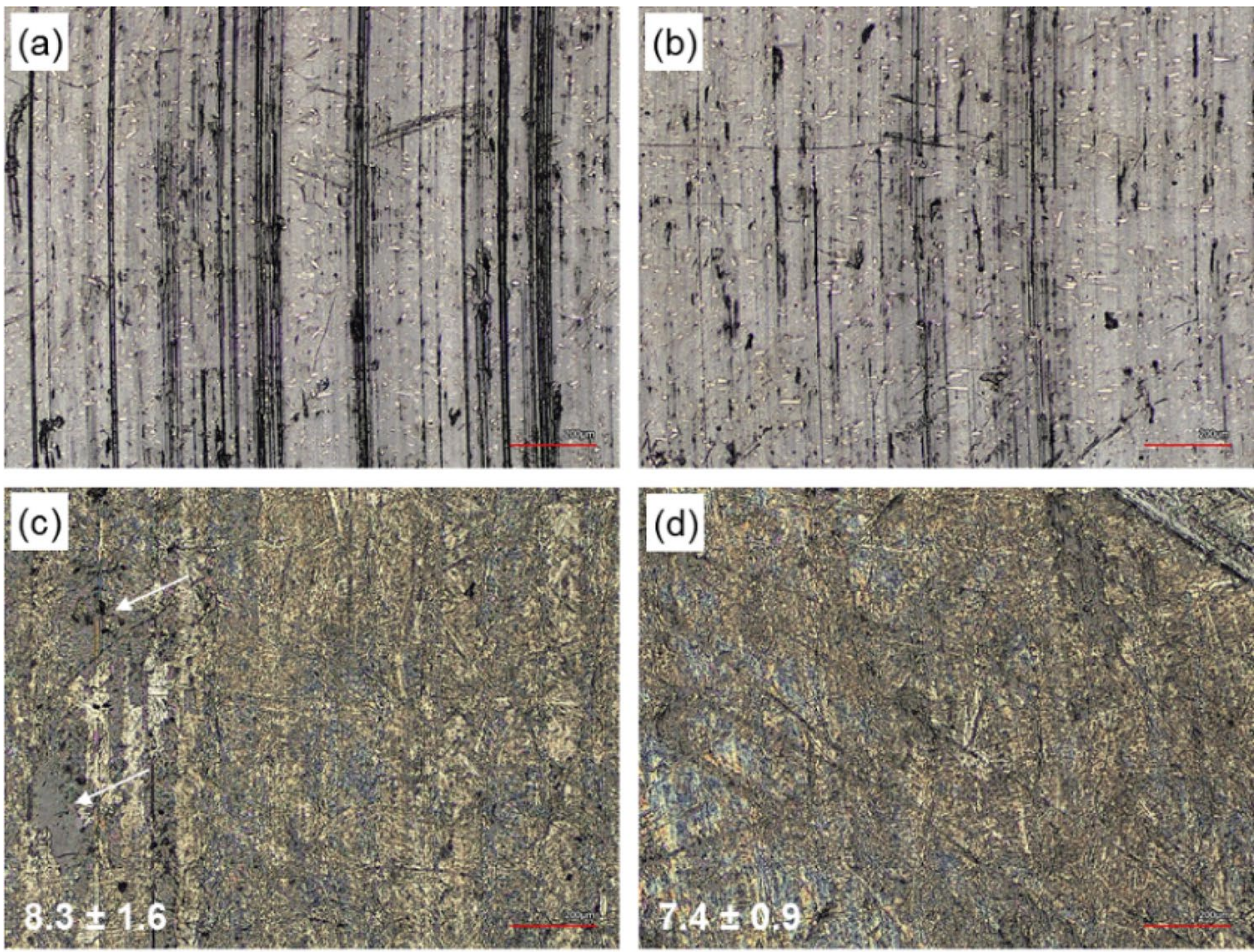

$26.9 \pm 0.2$
$29.7 \pm 2.5$ 
Fig. 7 Representative micrographs of $\mathbf{a} / \mathbf{b}$ polymer worn surfaces and c/d transfer films formed on the steel counterpart at $1 \mathrm{MPa}$ and $4 \mathrm{~m} / \mathrm{s}$ with $\mathbf{a} / \mathbf{c}$ increasing and $\mathbf{b} / \mathbf{d}$ decreasing velocity sequence. The sliding direction is from the top to the bottom. The scale is equal in all the images. The number within the images indicates the developed interfacial area ratio $\left(\mathrm{S}_{\mathrm{dr}}\right.$, in percentage) of the transfer films and the values below them are the $\mathrm{S}_{\mathrm{dr}}$ values (in percentage) of the steel disc as received
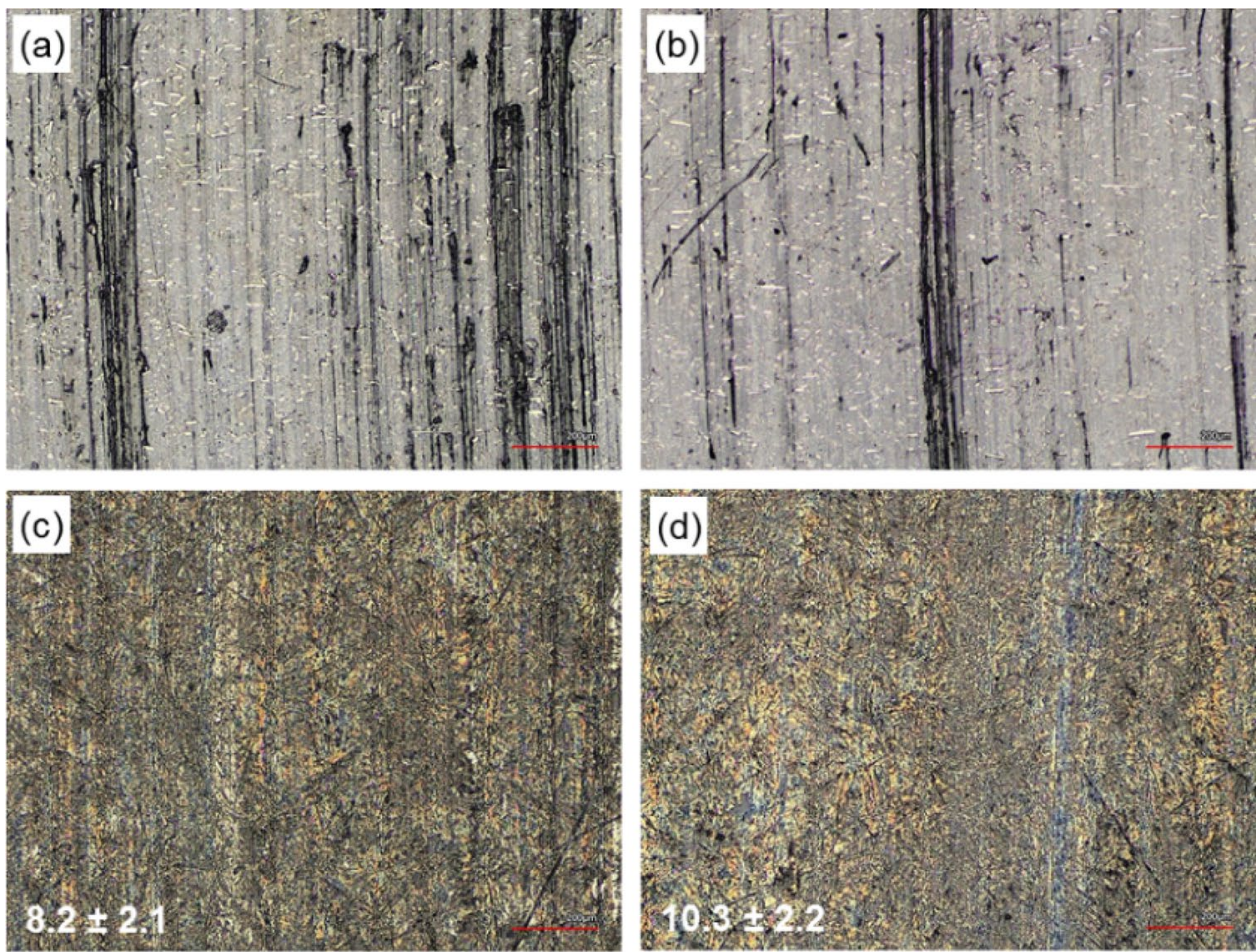

$21.1 \pm 3.9$

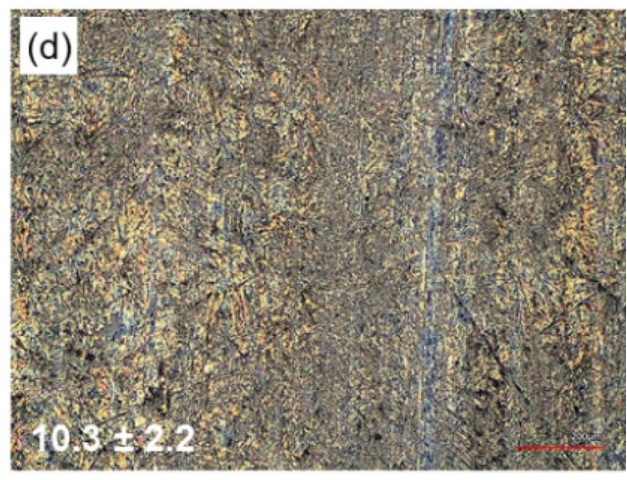

$23.2 \pm 0.1$
Fig. 8 Representative micrographs of $\mathbf{a} / \mathbf{b}$ polymer worn surfaces and c/d transfer films formed on the steel counterpart at $8 \mathrm{MPa}$ and $1 \mathrm{~m} / \mathrm{s}$ with $\mathbf{a} / \mathbf{c}$ increasing and $\mathbf{b} / \mathbf{d}$ decreasing velocity sequence. The sliding direction is from the top to the bottom. The scale is equal in all the images. The number within the images indicates the developed interfacial area ratio $\left(\mathrm{S}_{\mathrm{dr}}\right.$, in percentage) of the transfer films and the values below them are the $S_{\mathrm{dr}}$ values (in percentage) of the steel disc as received
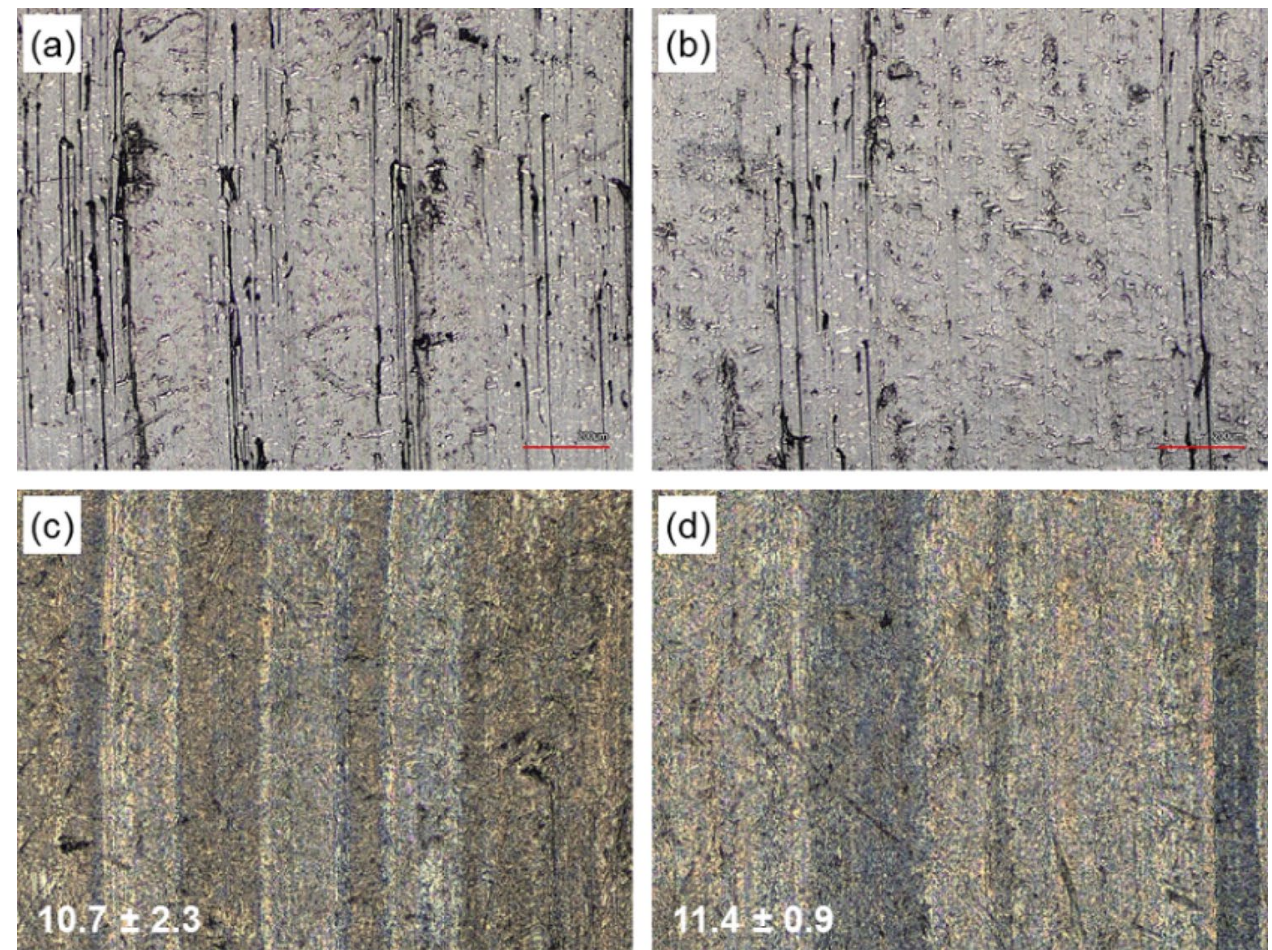

$25.9 \pm 1.5$

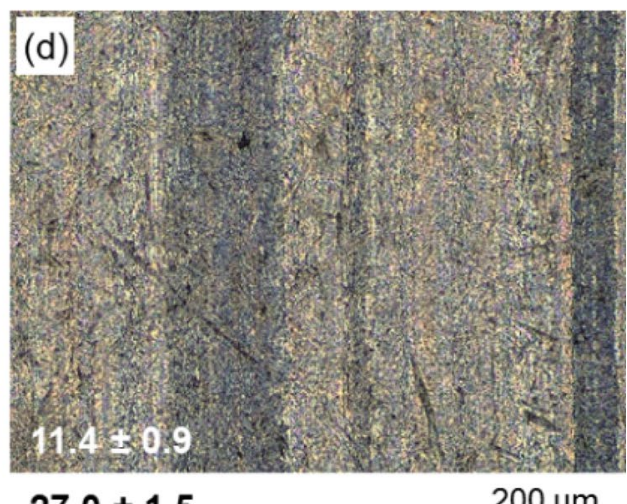

$27.0 \pm 1.5$

$200 \mu \mathrm{m}$ 
an abrasive wear, which leads to a high wear of the sample. In contrast, adhesion dominates the wear behavior between the polymer/steel sliding couple tested with continues reducing velocity (cf. Figure 6b). Analysis of the transfer films provides further evidence on the dependence of the friction and wear behavior of the PEEK composite on the sliding velocity sequences. Independent on the velocity sequences, all the wear tracks present low developed interfacial area ratio $\left(\mathrm{S}_{\mathrm{dr}}\right)$ compared to that of original surface of the steel disc as received, as is shown in Fig. 6c and d. The details for calculating $\mathrm{S}_{\mathrm{dr}}$ values can be found in the supporting information. This phenomenon reveals that deep grooves of the steel disc were stuffed by the transferred materials during the sliding process, which correlates with the low $\mathrm{S}_{\mathrm{dr}}$ values. Taking into account the dependence of the transfer film formation on the velocity sequences, it is found that the transfer film formed on the steel counterface with increasing sequence exhibits slightly higher $S_{\mathrm{dr}}$ value with higher scatter compared to that with decreasing one, which correlates with inhomogeneous formation of transfer films. In addition, thick leave-like transfer films can be clearly observed on the steel surface, as indicated by the white arrows in Fig. 6c, which is the another reason for the high wear under this velocity sequence condition. When the sliding velocity is raised to $4 \mathrm{~m} / \mathrm{s}$, it is interesting to notice that the difference between the worn surface morphologies under
Fig. 9 Representative micrographs of $\mathbf{a} / \mathbf{b}$ polymer worn surfaces and $\mathbf{c} / \mathbf{d}$ transfer films formed on the steel counterpart at $8 \mathrm{MPa}$ and $4 \mathrm{~m} / \mathrm{s}$ with $\mathbf{a} / \mathbf{c}$ increasing and $\mathbf{b} / \mathbf{d}$ decreasing velocity sequence. The sliding direction is from the top to the bottom. The scale is equal in all the images. The number within the images indicates the developed interfacial area ratio $\left(S_{\mathrm{dr}}\right.$, in percentage) of the transfer films and the values below them are the $S_{\mathrm{dr}}$ values (in percentage) of the steel disc as received
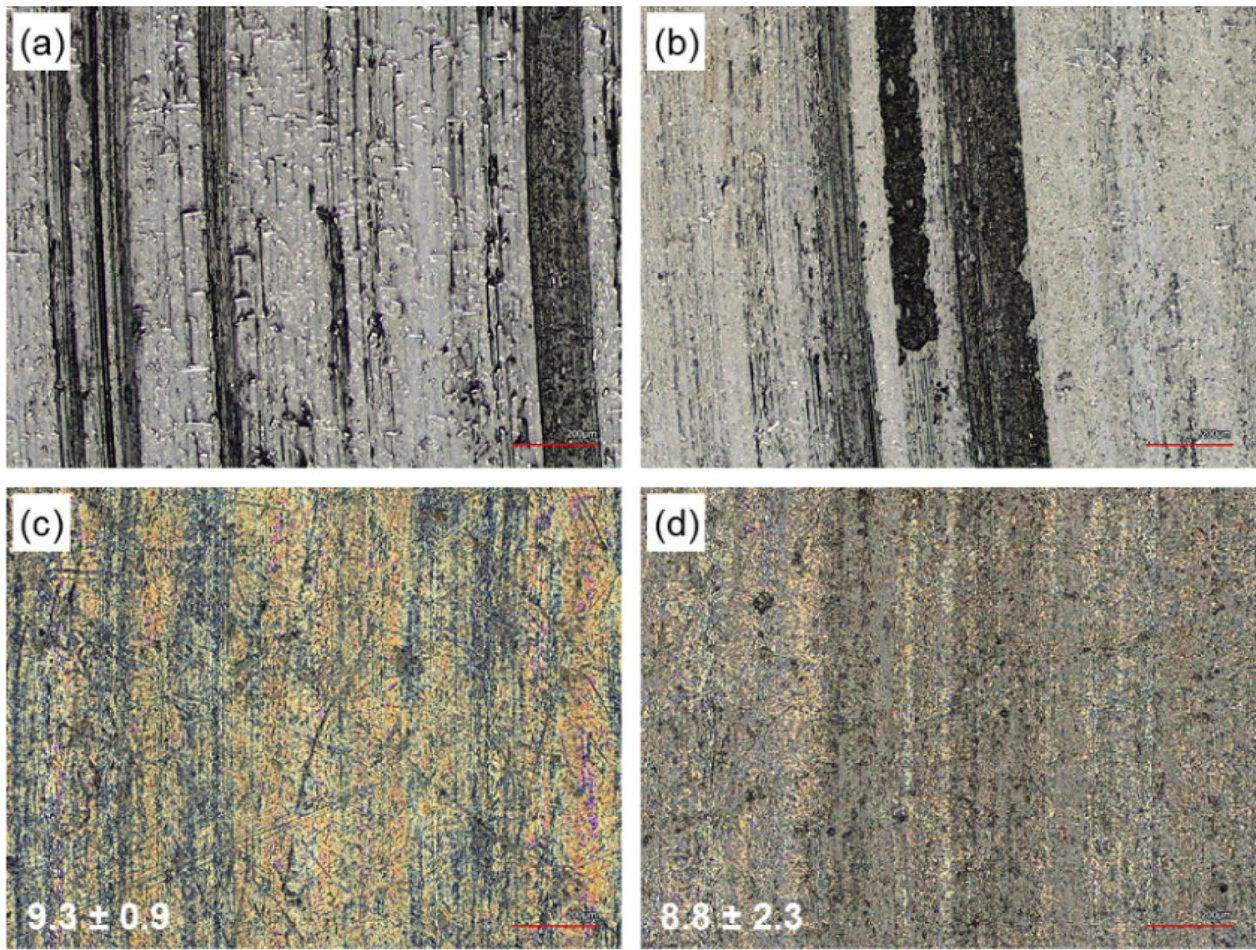

$22.6 \pm 1.3$ $200 \mu \mathrm{m}$
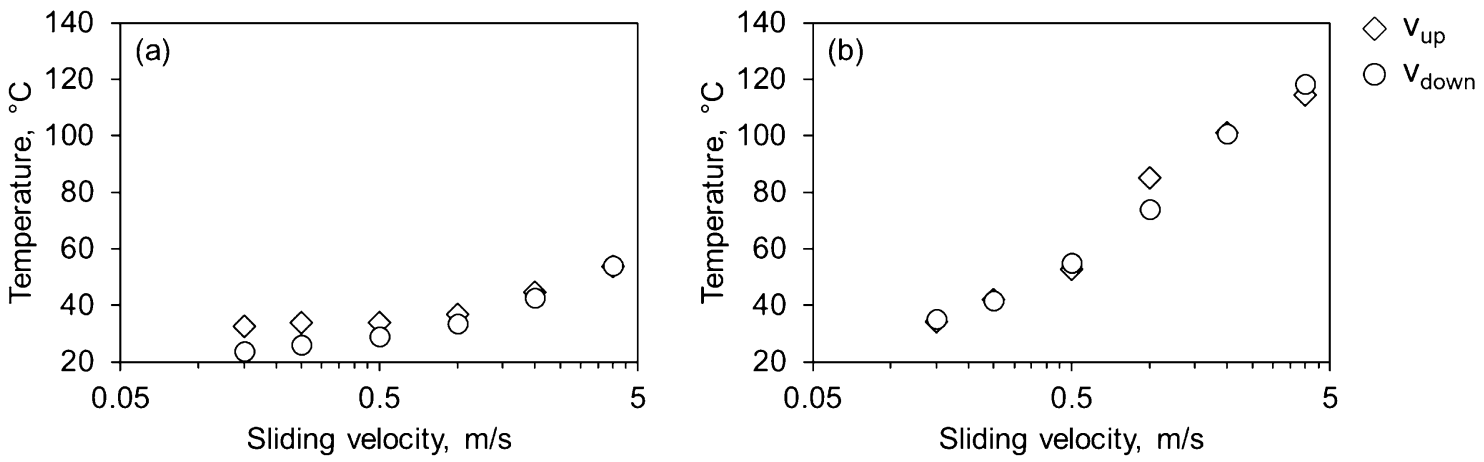

Fig. 10 Dependence of the estimated maximum contact edge temperature of the PEEK composite on the sliding velocity at $\mathbf{a} 1 \mathrm{MPa}$ and $\mathbf{b} 8$ $\mathrm{MPa}$ 
different velocity sequences becomes insignificant (cf. Figure $7 \mathrm{a}$ and $\mathrm{b}$ ). Both worn surfaces exhibit a nature of abrasion. Inspections of the transfer films reveal that diminishing velocity sequence causes inhomogeneous transfer film formation (high $\mathrm{S}_{\mathrm{dr}}$ value) indicating a high wear under this testing condition compared to that with increasing velocity sequence (Fig. 7c and d).

Figure 8 presents the worn surface morphologies of the PEEK composite and the transfer films tested with distinct velocity sequences at the pv-combination of $8 \mathrm{MPa}$ and 1 $\mathrm{m} / \mathrm{s}$. As can be seen in Fig. $8 \mathrm{a}$ and b, the PEEK composite presents similar patterns of the worn surface. Nevertheless, more deep ploughing furrows mainly resulted from the broken carbon fibers and the steel counterpart asperities can be clearly noticed on the worn surface during the sliding wear process with enhancing velocity sequence (cf. Figure $8 \mathrm{a}$ and Figure S2) [15], which correlate with the high friction and wear. In contrast, no obvious distinction of the transfer films can be observed under different sliding velocity conditions, as is shown in Fig. 8c and d. Increasing the velocity to 4 $\mathrm{m} / \mathrm{s}$ at $8 \mathrm{MPa}$ causes obviously different worn surfaces. The ploughing furrows are aggravated (cf. Figure $9 a$ and b). The PEEK composite suffers more abrasive wear under these load conditions and the distinction of both worn surfaces and the transfer films between different velocity sequences is marginal, which indicates similar friction and wear properties with different velocity sequences.

As is shown in Fig. 10a, the calculated maximum contact edge temperature (cf. Figure 1) of the polymer sample examined with increasing sliding velocity sequence at $1 \mathrm{MPa}$ is 5 to $10{ }^{\circ} \mathrm{C}$ higher than that with reducing velocity sequence up to $0.5 \mathrm{~m} / \mathrm{s}$. As is well known, thermoplastic materials display an easy-to-shear nature, when they are subjected at elevated temperatures. The distinction of the temperature leads to different load bearing capacity of the PEEK composite, which closely relates to the low friction and high wear of the PEEK composite with increasing sliding velocity sequence at $1 \mathrm{MPa}$ and slow sliding velocity. Therefore, the contact temperature plays a dominant role on determining the tribological properties of the PEEK composite under these sliding conditions. In contrast, the temperature is independent on the velocity sequences at high sliding velocities above $1 \mathrm{~m} / \mathrm{s}$ (cf. Figure 10a). Nevertheless, the specific wear rate strongly differs from each other with distinct sliding velocity sequences. Thus, the dominant wear mechanism is the abrasive nature and the different formations of the transfer films, as discussed above.

Regarding the temperature with distinct sliding velocity sequences at $8 \mathrm{MPa}$, it is found that the temperature difference becomes less pronounced compared to that at $1 \mathrm{MPa}$ (cf. Figure 10b). Interestingly, the PEEK composite displays a clear difference of the temperature examined with different velocity sequences at $8 \mathrm{MPa}$ and $1 \mathrm{~m} / \mathrm{s}$. The maximum

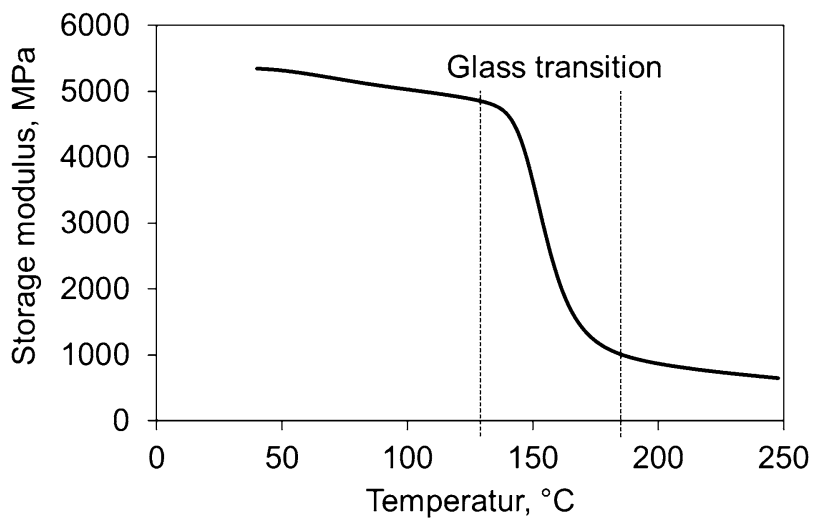

Fig. 11 Temperature-dependent evolution of the storage modulus of the PEEK composite

contact edge temperature with increasing sliding velocity sequence is $11^{\circ} \mathrm{C}$ higher than that with inverse velocity sequence under the same pv-condition (cf. Figure 10b), which is approximate $85^{\circ} \mathrm{C}$. Herein, it must be indicated that this temperature is the maximum sample boundary temperature. The difference of the real contact temperature over the whole contact region with different sequences of the velocity must be much more prominent, which means that the maximum contact temperature is significantly higher than $85^{\circ} \mathrm{C}$. The result of the dynamic mechanical thermal analysis shows that the glass transition range of the PEEK composite is between $130{ }^{\circ} \mathrm{C}$ and $180{ }^{\circ} \mathrm{C}$, in which little changing in the temperature can result in a dramatic alteration of the mechanical properties (Fig. 11). Below and above this region, the dependence of the mechanical properties on the temperature is insignificant. Therefore, it is believed that the real contact temperature of the sliding pair induced by the frictional heating with increasing velocity sequence may locate in this transition region. High temperature in this characteristic temperature region leads to a strong softening of PEEK, and therefore increasing adhesion between the PEEK sample and the transfer films as well as the steel counterpart surface. As a result, the friction coefficient and specific wear rate show obviously higher values.

\section{Conclusions}

In the present study, the dependence of the friction and wear properties of PEEK and its hybrid composite on the tribological histories were systematically studied. Interesting and useful results are gained and the following conclusions can be drawn:

(1). The influence of the velocity sequences on the friction behavior of pure PEEK is marginal. However, 
its wear resistance at the initial pv-levels exhibits a strong dependence on the sequences of the velocity. Once PEEK transfer films cover the steel counterpart surface during the initial pv-level, the effect of the velocity sequences on the specific wear rate of the following pv-levels vanishes.

(2). At a low pressure of $1 \mathrm{MPa}$, the friction coefficient of the PEEK composite is susceptible to distinct velocity sequences up to $0.5 \mathrm{~m} / \mathrm{s}$ and its wear resistance depends also on the sequences of the velocity in the studied range. In contrast, the velocity sequences exert much less impact on the friction and wear properties of the PEEK composite at a pressure of $8 \mathrm{MPa}$ except for the pv-combination of $8 \mathrm{MPa}$ and $1 \mathrm{~m} / \mathrm{s}$, under which the PEEK composite presents poor tribological performance with increasing velocity sequence due to its strong adhesion and easy-to-shear nature induced by the high temperature under this load condition.

(3). The tribological properties of both PEEK materials measured with different velocity sequences exhibit a clear correlation to the temperature of the sliding pair.

(4). Overall, adhesion and abrasion are the main tribological mechanisms, which strongly depend on the pv-levels and velocity sequences.

Supplementary Information The online version contains supplementary material available at https://doi.org/10.1007/s11249-021-01452-8.

Acknowledgements The authors thank German Research Foundation (DFG) for the financial support of this research project with the Grant No. SCHL 280/32-1. We also gratefully acknowledge Evonik Operations GmbH, Germany, SGL Carbon SE, Germany, Superior Graphite, Sweden, Venator Materials and Kronos International, Germany, for providing the experimental materials.

Funding Open Access funding enabled and organized by Projekt DEAL. This work was funded by German Research Foundation (DFG) with the Grant No. SCHL 280/32-1.

\section{Declarations}

Conflict of interest No conflict of interests for authors.

Open Access This article is licensed under a Creative Commons Attribution 4.0 International License, which permits use, sharing, adaptation, distribution and reproduction in any medium or format, as long as you give appropriate credit to the original author(s) and the source, provide a link to the Creative Commons licence, and indicate if changes were made. The images or other third party material in this article are included in the article's Creative Commons licence, unless indicated otherwise in a credit line to the material. If material is not included in the article's Creative Commons licence and your intended use is not permitted by statutory regulation or exceeds the permitted use, you will need to obtain permission directly from the copyright holder. To view a copy of this licence, visit http://creativecommons.org/licenses/by/4.0/.

\section{References}

1. Friedrich, K., Zhang, Z., Schlarb, A.K.: Effects of various fillers on the sliding wear of polymer composites. Compos. Sci. Technol. 65, 2329-2343 (2005). https://doi.org/10.1016/j.compscitech. 2005.05.028

2. Lu, Z.P., Friedrich, K.: On sliding friction and wear of PEEK and its composites. Wear 181-183, 624-631 (1995). https://doi.org/ 10.1016/0043-1648(95)90178-7

3. Jones, D.P., Leach, D.C., Moore, D.C.: Mechanical properties of poly (ether-ether ketone) for engineering applications. Polymer 26, 1385-1393 (1985). https://doi.org/10.1016/0032-3861(85) 90316-7

4. Ma, N., Lin, G.M., Xie, G.Y., Sui, G.X., Yang, R.: Tribological behavior of polyetheretherketone composites containing short carbon fibers and potassium titanate whiskers in dry sliding against steel. J. Appl. Polym. Sci. 123, 740-748 (2012). https://doi.org/ 10.1002/app.34502

5. Wang, J., Gu, M., Bai, S., Ge, S.: Investigation of the influence of $\mathrm{MoS}_{2}$ filler on the tribological properties of carbon fiber reinforced nylon 1010 composites. Wear 255, 774-779 (2003). https:// doi.org/10.1016/S0043-1648(03)00268-0

6. Pei, X.Q., Bennewitz, R., Schlarb, A.K.: Mechanisms of friction and wear reduction by carbon fiber reinforcement of PEEK. Tribol. Lett. 58, 42 (2015). https://doi.org/10.1007/s11249-015-0520-7

7. Jacobs, O., Jaskulka, R., Yan, C., Wu, W.: On the effect of counterface material and aqueous environment on the sliding wear of various PEEK compounds. Tribol. Lett. 58, 359-372 (2005). https://doi.org/10.1007/s11249-004-2766-3

8. Nunez, E.E., Polycarpou, A.A.: The effect of surface roughness on the transfer of polymer films under unlubricated testing conditions. Wear 326-327, 74-83 (2015). https://doi.org/10.1016/j. wear.2014.12.049

9. Josch, L.E., Götz, V., Römer, C., Konchakova, N., Emrich, S., Wagner, W., Müller, R., Kopnarski, M., Schlarb, A.K.: Influence of the shaping on tribological properties of PEEK-coated U-shaped metal-profiles. Adv. Eng. Mater. 15, 830-836 (2013). https://doi.org/10.1002/adem.201200274

10. Zhang, G., Tria, S., Schlarb, A.K., Elkedim, O.: Tensile and tribological behaviors of PEEK/nano- $\mathrm{SiO}_{2}$ composites compounded using ball milling technique. Compos. Sci. Technol. 68, 30733080 (2008). https://doi.org/10.1016/j.compscitech.2008.06.027

11. Bayerl, T., Schlarb, A.K.: Welding of tribologically optimized polyetheretherketone films with metallic substrates. Tribol. Int. 43, 1175-1179 (2010). https://doi.org/10.1016/j.triboint.2009.12. 018

12. Friedrich, K., Schlarb, A.K.: Tribology of polymer nanocomposites, 2nd edn. Elsevier B.V, Oxford (2013)

13. Zhang, G., Chang, L., Schlarb, A.K.: The roles of nano-SiO ${ }_{2}$ particles on the tribological behavior of short carbon fiber reinforced PEEK. Compos. Sci. Technol. 65, 1029-1035 (2009). https://doi. org/10.1016/j.compscitech.2009.01.023

14. Chang, L., Zhang, Z., Zhang, H., Schlarb, A.K.: On the sliding wear of nanoparticle filled polyamide 66 composites. Compos. Sci. Technol. 65, 3188-3198 (2006). https://doi.org/10.1016/j. compscitech.2005.02.021

15. Lin, L.Y., Schlarb, A.K.: Effect of the varied load conditions on the tribological performance and the thermal characteristics of PEEK-based hybrid composites. Tribol. Int. 101, 218-225 (2016). https://doi.org/10.1016/j.triboint.2016.04.025

16. Bahadur, S.: The development of transfer layers and their role in polymer tribology. Wear 245, 92-99 (2000). https://doi.org/10. 1016/S0043-1648(00)00469-5

17. Bahadur, S., Sunkara, C.: Effect of transfer film structure, composition and bonding on the tribological behavior of polyphenylene 
sulfide filled with nano particles of $\mathrm{TiO}_{2}, \mathrm{ZnO} \mathrm{CuO}$ and $\mathrm{SiC}$. Wear 258, 1411-1421 (2005). https://doi.org/10.1016/j.wear.2004.08. 009

18. Ye, J.X., Burris, D.L., Xie, T.: A Review of transfer films and their role in ultra-low-wear sliding of polymers. Lubricants 4, 4 (2016). https://doi.org/10.3390/lubricants4010004

19. Mazza, L., Trivella, A., Grassi, R., Malucelli, G.: A comparison of the relative friction and wear responses of PTFE and a PTFEbased composite when tested using three different types of sliding wear machines. Tribol. Int. 90, 15-21 (2015). https://doi.org/10. 1016/j.triboint.2015.04.001

20. Yeo, S.M., Polycarpou, A.A.: Fretting experiments of advanced polymeric coatings and the effect of transfer films on their tribological behavior. Tribol. Int. 79, 16-25 (2014). https://doi.org/10. 1016/j.triboint.2014.05.012

21. Song, F.Z., Wang, Q.H., Wang, T.M.: Effects of glass fiber and molybdenum disulfide on tribological behaviors and PV limit of chopped carbon fiber reinforced Polytetrafluoroethylene composites. Tribol. Int. 104, 392-401 (2016). https://doi.org/10.1016/j. triboint.2016.01.015

22. Oster, F.: Hochtemperaturbeständige polymer-beschichtungen für tribologische anwendungen. Ph.D. thesis. Technische Universität Kaiserslautern, Kaiserslautern (2005).

23. Lin, L.Y., Schlarb, A.K.: Recycled carbon fibers as reinforcements for hybrid PEEK composites with excellent friction and

\section{Authors and Affiliations}

\section{Leyu Lin $^{1}$ (D) Y Yuxiao Zhao ${ }^{1}$ - Chi Hua ${ }^{1}$ - Alois K. Schlarb ${ }^{1,2,3}$}

1 Chair of Composite Engineering (CCe), Technische Universität Kaiserslautern (TUK), Gottlieb-Daimler-Str. Bld. 44, 67663 Kaiserslautern, Germany

2 Research Center OPTIMAS, Technische Universität Kaiserslautern (TUK), 67663 Kaiserslautern, Germany wear performance. Wear 432-433, 202928 (2019). https://doi.org/ 10.1016/j.wear.2019.202928

24. Lin, L.Y., Pei, X.Q., Bennewitz, R., Schlarb, A.K.: Tribological response of PEEK to temperature induced by frictional and external heating. Tribol. Lett. 67, 52 (2019). https://doi.org/10.1007/ s11249-019-1169-4

25. Kamerling, S., Schlarb, A.K.: Magnesium hydroxide - A new lever for increasing the performance and reliability of PA66/steel tribosystems. Tribol. Inter. 147, 106271 (2020). https://doi.org/ 10.1016/j.triboint.2020.106271

26. Ecke, N., Schott, M., Schlarb, A.K.: A comparison of analytical methods for estimating temperatures in simple sliding contacts. J. Plas. Technol. 17, 94-117 (2018)

27. Ye, J., Khare, H.S., Burris, D.L.: Transfer film evolution and its role in promoting ultra-low wear of a PTFE nanocomposite. Wear 297, 1095-1102 (2013). https://doi.org/10.1016/j.wear.2012.12. 002

Publisher's Note Springer Nature remains neutral with regard to jurisdictional claims in published maps and institutional affiliations. Qingdao University of Science and Technology, Qingdao 266042, China 